\title{
Criança, Meio Ambiente e Cidadania
}

\section{Léa Tiriba}

\section{Mary Suely S. Barradas}

Núcleo de Educação do Instituto de Políticas Alternativas para o Cone Sui (PACS)

"Existe uma ecologia das idéias danosas, assim como existe uma ecologia das ervas daninhas"

Considerando, por um lado, a necessidade urgente de que os movimentos sociais formulem propostas de políticas públicas para a educação infantil e pressionem os governos a executarem estas políticas; e, por outro lado, considerando a necessidade de que seja assegurada a qualidade dos serviços às crianças que já freqüentam creches e préescolas, este artigo tem como objetivo:

1. explicitar uma concepção de educação integral em que uma das questões centrais é a construção de uma convivência com a Natureza que faça com que o ser humano se sinta parte dela e não o seu senhor. 2. apresentar algumas reflexões a partir do que consideramos, hoje, uma ecessidade urgente: a emergência de práticas educativas que ofereçam aconchego e proteção e ampliem as possibilidades de movimentação, expressão e integração com a natureza; práticas educativas que preservem a singularidade, admirem a multiplicidade humana, assegurem o aprendizado da cooperação e, assim, contribuam para o pleno exercício da cidadania.

\section{Introdução}

No Brasil de hoje - em que todos os anos a escola pública deixa de atender a um número considerável de crianças e ocorrem taxas altíssimas 
de repetência e de evasão nas primeiras séries do primeiro grau — qualquer projeto que vise à solidariedade, à humanização, à paz social, terá, antes de tudo, que garantir o acesso da criança à escola.

Para as crianças pequenas, de 0 a 6 anos, esta é uma questão essencial. Embora sua educação, em creches e pré-escolas, esteja assegurada pela Constituição Federal, o fato é que, segundo dados do último censo (1990), apenas 5\% das crianças entre 0 c 3 anos freqüentam creches; e $32 \%$ das que tem entre 4 e 6 anos estão matriculadas cm préescolas.

Esta situação coloca para os profissionais de educação uma dupla responsabilidade: a primeira é a de promovermos uma articulação política, que inclua as famílias das crianças, de forma que tenhamos condições de formular propostas de políticas públicas em educação infantil e de pressionar o poder público no sentido de que se concretizem as propostas apontadas; a segunda responsabilidade é a de assegurarmos a qualidade dos serviços oferecidos às crianças que já freqüentam creches e pré-escolas.

Como expusemos anteriormente, essas crianças constituem uma pequena parcela da população brasileira entre 0 e 6 anos de idade. Citando um outro exemplo, de acordo com dados de 1991, apresentados pelo Instituto de Planejamento do Rio de Janeiro (IPLAN-RIO), havia no município, nesta faixa etária, cerca de 600 mil crianças. Deste total, aproximadamente 82 mil (14\%) freqüentavam creches e pré-escolas. E o mais grave - mais de 50 mil dessas crianças estavam matriculadas na rede particular.

Estes dados nos permitem uma visão mais ampla da situação social e política em que se insere o trabalho dos educadores de creches e préescolas, nos permitem uma idéia clara de que sua prática profissional está dirigida para uma parcela mínima da população brasileira que se encontra na faixa etária entre 0 e 6 anos.

Conscientes desta realidade é hora de nos perguntarmos:

Quais os objetivos mais gerais c qual o caráter político do trabalho realizado pelos educadores que atuam junto às crianças pequenas? Seu trabalho contribui para a formação de seres humanos amorosos, solidários, cooperativos, encontrados consigo mesmos e integrados na sociedade em que vivem - seres, por tudo isto, capazes de participar e interferir em 
um processo de luta pela transformação de uma realidade social marginalizadora? Ou contribui para a reprodução de uma sociedade dividida entre privilegiados c oprimidos, promovendo a escolarização precoce daqueles que, por sua situação de classe, estão destinados a ocupar os postos de poder?

Quem são as crianças matriculadas nas instituições da rede privada?

Moradoras de centros urbanos e pertencentes, em sua maioria, a famílias de classe média e alta, são crianças atendidas em suas necessidades básicas de habitação, alimentação, saúde, educação. Seus pais em geral trabalham fora, o que as obriga a desfrutarem pouco de sua companhia. Cada vez mais um número maior delas ingressa na creche antes de completar 1 ano de idade. Por outro lado, a estrutura nuclear de suas famílias também não lhes facilita o convívio cotidiano com tios, avós, primos. Assim, sob o cuidado de babás ou empregadas domésticas, passam parte do dia entre a televisão e as atividades para as quais dependem da companhia de adultos.

E quem são as crianças das classes populares que freqüentam as instituições de educação infantil?

São, $\mathrm{cm}$ sua quase absoluta maioria, crianças moradoras das favelas e periferias dos grandes c médios centros urbanos. Vivem em regiões onde são precárias as condições de habitação, higiene, saúde e lazer. Como as crianças das classes médias, desfrutam pouco - ainda menos que estas - da companhia de seus pais, que, além de trabalharem oito ou mais horas diárias, ainda desperdiçam boa parte de seu tempo no trajeto de ida ao trabalho c retorno à casa. Há, ainda, os afazeres domésticos, que ocupam parte da noite e, para as mulheres, principalmente, se estendem pelos finais de semana.

A falta de tempo e os parcos salários de seus pais são fatores que, combinados, determinam um lazer rarefeito e limitado ao local de moradia e arredores. Ir ao cinema, ao teatro, a um parque de diversões, fazer passeios a sítios ou à orla marítima são atividades que nunca ou raríssimamente são oferecidas a essas crianças.

Nos bairros populares onde residem, são, geralmente, mais frequientes e solidárias as trocas sociais entre os vizinhos. Entretanto, em centros urbanos como o Rio de Janeiro, por exemplo, a violência gerada 
pelo desemprego e pela miséria, além daquela produzida pelo narcotráfico e pela própria polícia, vem fazendo com que o espaço das ruas, das praças, seja cada vez menos utilizado peias crianças, em especial as pequenas.

Muitas das creches e pré-escolas existentes nessas regiões surgiram, justamente, da necessidade de proteção às crianças, cujos pais, por suas condições materiais, não têm como assegurar sequer o mínimo indispensável a um crescimento sadio. Essas instituições vem cumprindo, para as poucas crianças das classes populares que a elas têm acesso, a função de assegurar a sua sobrevivência. Cumprem, portanto, uma função assistencial e estão, em sua grande maioria, muito distantes de uma concepção c de uma prática educativa inteligente, lúdica e criativa.

Podemos facilmente verificar que o crescimento desordenado dos centros urbanos afasta progressivamente das ruas c das praças, tanto as crianças das classes médias quanto as das classes menos favorecidas, impedindo um exercício "natural" de cidadania, dificultando o encontro c a troca espontânea entre as pessoas de diferentes classes sociais, impedindo o exercício do uso democrático do espaço. Onde e com quem brincam, por exemplo, as crianças que moram $\mathrm{cm}$ prédios sem playground, com ruas tomadas pelo comércio e pelo trânsito dos carros? Onde brincam c com quem brincam as crianças que vivem nas favelas $\mathrm{cm}$ que não há áreas de lazer? Para estas e aquelas, assim como para outras, que vivem $\mathrm{cm}$ condições semelhantes, jogar bola, soltar pipa, subirem árvores, integrarse com a natureza, fazer amigos, grupalizar-se não são atividades corriqueiras, cotidianas. A arquitetura, a falta de espaço, a violência da cidade, dificultam, "desnaturalizam", estes aprendizados.

Por tudo isso, podemos afirmar que tanto as crianças das classes média e alta quanto as que integram as classes menos favorecidas são limitadas em seu desenvolvimento pleno por uma sociedade desumanizada e desumanizadora.

Diante desta realidade nos perguntamos sôbre as múltiplas necessidades que essas crianças trazem consigo para as escolas de educação infantil e, por conseguinte, sôbre as funções que estas instituições devem exercer, caso compreendam que também é de sua responsabilidade satisfazê-las. Não importa a denominação da instituição que as receba: jardim de infância, lar, pré-escola ou orfanato. Importa que atendam, todas 
elas, a crianças na faixa entre $\mathrm{O}$ e 6 anos, que trazem para a escola a necessidade não apenas de entender o mundo natural e humano em que vivem, mas de vivenciar plenamente este mundo c aprender a compreendêlo, a respeitá-lo c a reconstruí-lo.

Mesmo estando, principalmente a pré-escola, hoje, mais comprometidas com os vários aspectos do desenvolvimento infantil, temos assistido nos últimos anos a uma proliferação de escolas que privilegiam o desenvolvimento racional. Preocupadas com a aquisição de conhecimentos, ou mesmo atentas ao processo de sua construção, desenvolvem propostas que desvinculam o pensar do sentir, do con-viver. Propostas tecnicamente inovadoras, porém não comprometidas com a formação de seres humanos integrais. Funcionam assim como a ante-sala de uma rede de ensino (de $1^{\circ}, 2^{\circ}$ c $3^{\circ}$ graus), comprometidas apenas, ou principalmente, com a apropriação competente do conhecimento já sistematizado. Até mesmo o questionamento de normas e valores que regem nossa sociedade é feito de forma intelectual, distante, sem se desdobrar na criação de uma escola que possibilite a vivência de novas atitudes/concepções diante da sociedade, da natureza c do planeta.

É verdade que não se pode negar uma evolução do trabalho das instituições de educação infantil. Há 15 anos a maioria delas exercia uma simples função de guarda: tomavam conta das crianças e ofereciam atividades e materiais para entrctê-las, enquanto aguardavam o retorno dos pais. Hoje, a situação é outra: um número cada vez maior de educadores compreende que é justamente na faixa entre 0 c 6 anos que os seres humanos constróem não apenas os traços fundamentais de sua personalidade como também as estruturas básicas de sua inteligência. Em conseqüência desta compreensão, as propostas pedagógicas avançaram no sentido de favorecer o processo de construção dessa inteligência. Entretanto, é hora de avançar mais: analisar a realidade $\mathrm{cm}$ que vivemos c repensar o trabalho $\mathrm{cm}$ função da gama de necessidades geradas pelas condições de vida a que as crianças estão submetidas. Estas necessidades não dizem respeito apenas, nem principalmente, à aquisição dos conhecimentos que a humanidade produziu ao longo de sua existência. São mais amplas c estão relacionadas a um viver de forma integral, em 
uma nova sociedade democrática cm que não basta ser inteligente; c preciso ser amoroso, criativo, autônomo, cooperativo, estar conectado com a natureza e atento às condições de vida no planeta.

Portanto, refletindo sobre as condições de vida das crianças com quem trabalhamos, e entendendo a creche e a pré-escola enquanto responsáveis não apenas pela transmissão at conhecimentos já sistematizados, mas como co-responsáveis pela formação de sujeitos, concluiremos que precisamos ampliar as suas funções, precisamos assumir funções de guarda, maternas e paternas, pedagógicas, socializadoras c humanizadoras.

Esta compreensão nos compromete com um esforço de construção coletiva de uma pedagogia que, além de oferecer aconchego e proteção, amplie as possibilidades de movimentação, expressão e integração com a natureza; uma pedagogia que preserve a singularidade, admire a multiplicidade humana, assegure o aprendizado da cooperação e da autonomia e contribua para a formação plena da cidadania.

Como construir uma pedagogia pré-escolar comprometida com a formação integral de nossos pequenos cidadãos? Acreditamos que o ponto de partida é a reflexão permanente, em cada escola, sobre o trabalho concreto, cotidiano, que seus educadores já realizam. Esta reflexão coletiva sobre as práticas individual e de grupo — aliada à apropriação de conhecimentos já sistematizados que favoreçam o aprofundamento da reflexão - é que nos ajudará a abrir novos caminhos, a construir novas práticas que correspondam às necessidades que a realidade apresenta. Assim, mediante a integração permanente e crescente entre ação e reflexão - entre teoria c prática — , nosso trabalho se constitui praxis.

Em que medida o trabalho educativo-pedagógico atende ao conjunto de necessidades (fisicas, emocionais, intelectuais, sociais) que as crianças trazem para a escola nos dias de hoje? É papel da creche e da pré-escola atendê-las? Nossa prática educativa está comprometida com a formação integral das crianças ou limita-se a alguns dos aspectos do seu desenvolvimento? Estes questionamentos podem dar início ao processo de reflexão e transformação do trabalho que realizamos hoje. 
Movimento c vida

Sabemos que se movimentar é uma necessidade vital, que é através do movimento que os seres humanos chegam a conhecer a si próprios $\mathrm{c}$ a realidade à sua volta.

Entretanto, a pré-escola urbana - que atende a crianças com tão poucas oportunidades cotidianas de se movimentar livremente - oferece pouco tempo para esta atividade. Um tempo maior é dedicado, nas mais tradicionais, a organização das crianças, ao aprendizado de hábitos c atitudes c à transmissão de conhecimentos.

Nas escolas experimentais, ou alternativas, como preferirmos denominá-las, as atividades de movimentação ocorrem com maior freqüência, mas são, geralmente, limitadas por um objetivo pedagógico. Assim, ocorre $\mathrm{cm}$ muitas escolas que estas atividades sejam propostas não porque do ponto de vista das crianças, sob vários aspectos, elas são fundamentais, mas principalmente porque, do ponto de vista do educador, o movimento amplo é a base do movimento fino, e é este que assegura o aprendizado da escrita. Além disso, como a partir dos 2 anos a preocupação principal é com o desenvolvimento da capacidade humana de simbolizar, as atividades de movimentação livre tornam-se cada vez mais raras: ocorrem na hora do recreio ou quando propostas como suporte concreto para aquilo que se pretende simbolizar/representar.

Nao há dúvida de que este trabalho é importante. Entretanto, ele tem uma finalidade delimitada pelo professor, que, via de regra, não está atento a uma necessidade maior de expressão, de desenvolvimento integral através do movimento.

Quando uma criança que tem medo de pular consegue, com ou sem a ajuda do adulto, realizar esta façanha, significa que $\mathrm{cm}$ vários aspectos ela cresceu. Ampliou suas possibilidades fisicas, está mais segura de sua própria capacidade de enfrentar e superar desafios, está feliz pelo fato de poder unir-se a seus companheiros em brincadeiras de que antes ficava excluída. Portanto, além de um desenvolvimento intelectual, que envolve 
modificações cm suas "noções" de espaço, tempo e causa, este novo aprendizado trouxe sensações e sentimentos que alteraram, ampliaram, seu universo emocional c social; que ampliaram, conseqüentemente, o seu campo de aprendizagem.

É preciso lembrar, cm especial para os educadores que têm seu trabalho fundamentado na teoria piagetiana, que as crianças pequenas são sensório-motoras não apenas do ponto de vista intelectual. Elas são sensório-motoras enquanto natureza integral, pois é através do movimento de seu corpo c das sensações provocadas por sua relação direta e inteira com o mundo humano c natural que elas constróem também referências afetivas c sociais.

\section{A vida como objeto $\mathrm{c}$ instrumento do ato de conhecer a vida}

Nos grandes centros urbanos, nem mesmo nos finais de semana as crianças têm a possibilidade de vivenciar experiências de contato direto com a natureza. As mais pobres, porque as famílias não dispõem de recursos para o lazer (inúmeras crianças que vivem $\mathrm{cm}$ cidades litorâneas jamais viram o mar!). As de classe media $\mathrm{c}$ alta, porque seus pais privilegiam outras atividades como ir ao teatro, ao cinema, passear no shopping Center...

- Sc ele brinca na terra, na areia...? Deixa eu ver... Contato com a terra teve sim: um dia quando descolou um taco do assoalho...

- O leite vem do saco e o peixe nasce apertado na latinha.

Depoimentos como estes denunciam uma situação nada favorável a uma integração necessária entre ser humano c natureza, isto é, entre o sujeito capaz de conhecer e transformar c o objeto a ser descoberto e recriado - a VIDA.

Não é demais relatar uma situação vivenciada por nós e por uma criança, situação esta que pode ilustrar o que pretendemos questionar:

Uma tarde, pedimos que Tati retirasse os pratos da mesa c pusesse, no canteiro do quintal, o caroço do abacate que havíamos comido no lanche. Pouco depois, ela veio até a cozinha com uma pergunta: 
— Eu já coloquei o caroço do abacate na terra... Vai nascer o que? A árvore ou a fruta?

Demoramos a entender a dúvida de Tati. Fizemos muitas perguntas a ela. Tantas quantas ela fazia a nós. E acabamos descobrindo que, embora ela conhecesse e repetisse de memória todas as partes que compõem um vegetal, não compreendia que cada uma delas é resultado de um processo integrado, global.

Tati estava com 11 anos. Desde pequenina, na escola, várias vêzes havia apreendido a fazer germinar uma semente de feijão: pegava o algodão, molhava, assentava os carocinhos e esperava a haste aparecer, crescer, nascer uma folhinha c depois morrer. Para os professores aquilo era uma experiência concreta, mas, para ela, uma difícil abstração: impossível trazer para o seu prato de comida - imagine, feijão! — aquele arbustozinho fininho, comprido.

Como tantas outras crianças, moradoras de centros urbanos, Tati jamais havia vivenciado o nascimento de um animal. Contrariando sua experiência concreta, que lhe apresentava o leite surgindo de sacos c peixes de uma pequena lata, havia aprendido, através dos livros c da informação dos adultos, que animais mamíferos produzem leite c peixes vivem no mar.

Não teve oportunidade ao longo de sua vida de vivenciar cotidianamente um processo de integração com a terra, a água, o ar, como fontes primeiras da vida. E, com base nesta experiência afetiva e cognitiva, construir uma concepção de si mesma, da espécie e do planeta enquanto fruto de uma evolução natural, integrada, una.

As "experiências concretas" sugeridas pela escola c as informações obtidas de forma teórica não apenas não foram capazes de propiciar esta vivência c esta compreensão, como talvez tenham até fortalecido a concepção de ser humano desvinculado da vida natural, que entende mas não compreende a vida, c, por isso, não é capaz de estruturar a si mesmo e a sociedade de forma integrada, harmonizada com a natureza.

É possível, trancados entre quatro paredes, convivendo com representações da vida concreta, tal qual ela se manifesta na natureza, conhecermos em sentido pleno, a natureza, a vida? Não. Não é possível 
amar, respeitar, defender algo com o qual não convivemos e não estabelecemos uma relação afetiva, apenas o conhecemos intelectualmente. $\mathrm{O}$ amor, o respeito, não se aprendem simplesmente através de teorias. São sentimentos que se constróem, e se incorporam a partir da vivência física c espiritual; através de uma relação inteira de corpo/emoção/razão com o universo maior do qual somos parte.

Desde a pré-escola incentivamos as crianças à aquisição de um conhecimento distanciado da natureza. Em geral, fechadas entre quatro paredes, eventualmente levadas a passeios ao jardim zoológico ou a um parque, as crianças ouvem histórias, desenham, cantam, pintam, dramatizam. Com pedaços de madeira fazem pilhas, enfileiram, utilizam blocos lógicos para classificar, ordenar, seriar. Folheiam livros, observam gravuras c manuseiam miniaturas de plástico para conhecer animais. O material concreto com que trabalham são, geralmente, representações do mundo natural.

Nós, educadores, parecemos não perceber que do lado de fora está, ou poderá estar, aquilo sôbre o que se estuda lá dentro. Não percebemos que além das miniaturas de plástico e de livros que falam de leões, girafas c elefantes, do lado de fora, estão gatos, cachorros, porcos, pássaros, ratos c baratas - animais com os quais convivemos, mas que, na escola, raramente se constituem objeto de investigação das crianças.

Nossas creches c pré-escolas esquecem que a vida é colorida. Utilizam toquinhos de madeira para ensinar as cores às crianças ao invés de levá-las a sentir c a observar o céu, as árvores, a terra, as cores da vida, da ma, das roupas, das casas.

Sobra pouco tempo (quando sobra) para sentir o sol, mexer na terra, plantar, colher, não pensar $\mathrm{cm}$ nada, brincar com água, senti-la no corpo...

Quando as crianças, ao ar livre, descobrem formigas trabalhando, ou juntam-se para observar uma aranha que tece sua teia, logo chegamos nós, seus professores, para atrapalhar um processo de integração e conhecimento. Não percebemos que ali está algo vivo, que deve ser/ conhecido naquele momento, porque é naquele momento que as crianças estão interessadas nele. Ao invés de atrapalhar, nossa intervenção de educadores deveria ser a de reunir o grupo, participar junto, incentivar e 
coordenar um processo de investigação que se inicia ali, junto às formigas, c que se estende, através da experiência concreta, da representação c da consulta a livros, a outras formas de vida animal ou a outros objetos de conhecimento que vão se constituindo ao longo do trabalho de pesquisa. Este deveria ser o sentido de trabalhar a partir do interesse c do conhecimento das crianças. Mas não há tempo, acabou o recreio: é hora de voltar às quatro paredes c só aqui "conhecer". Como se estudar nada tivesse a ver com vivenciar. Como se conhecimento nada tivesse a ver com a vida. Como se a ciência, as artes c a cultura não fossem o resultado de uma vontade humana de se integrar c se entregar à ela.

Herdeiros do pensamento cartesiano, vivemos na escola, ainda, o primado da razão. E, mesmo quando tentamos abraçar a dialética, supervalorizamos os processos mentais. Esquecemos que não basta pensar dialcticamcntc:é preciso vivenciar dialeticamente o processo do conhecer. Em conseqüência, na escola, pesquisamos à distancia: classificamos, organizamos, analisamos o todo c as partes, identificamos as contradições. Mas não somos capazes de compreender porque não buscamos uma relação dialética entre sujeito $\mathrm{c}$ objeto, não trabalhamos pedagogicamente uma relação inteira, não apenas racional, mas corporal, sensitiva, emocional, intuitiva, prazerosa, com a realidade natural c social que pretendemos conhecer.

\section{Criança c cidadania}

Pelo que foi dito, pode parecer que nós, educadores de creches e pré-escolas, não devemos dar importância aos processos de construção da lógica, da razão. Por isto, vale afirmar que não se trata de ignorá-la. Não valorizá-la significaria desprezar o esforço da natureza em se elaborar, de forma a criar seres capazes de se "distanciar" dela e representar, operar, abstrair, para poder transformá-la. Mas não podemos esquecer que somos mais que razão. Somos sensibilidade, somos afeto, somos fundamentalmente criação, invenção.

Uma educação que se pauta apenas pela racionalidade não libertará o ser humano dos impasses irracionais tutelados pela primazia da lógica e 
da técnica, que tem conduzido o homem a um vazio de referências, tornando-o despotencializado, descrente e dcsconhecedor de si próprio.

Trata-se, por isto, de construirmos uma praxis educativa que assuma o ser humano $\mathrm{cm}$ sua integralidade; uma educação omnilateral e omnidimensional que, como afirma Marcos Arruda, "abrange todos os campos da realidade humana $\mathrm{c}$ natural e todas as dimensões existenciais do ser humano".

Esta educação deverá contribuir para reverter um divórcio, um profundo desequilíbrio, entre nossos pensamentos c sentimentos, valores c atitudes, estruturas sociais c políticas. Desequilíbrio que, na opinião de Fritjof Capra, c gerado pelo sistema social de que somos parte c que enfatizando a auto-afirmação, a análise, o conhecimento racional c a competição, cm detrimento da integração, da síntese, da sabedoria intuitiva e da cooperação - vem gerando crises sociais, ecológicas, morais e existenciais.

Mészáros, interpretando Marx, nos diz que seu conceito de alienação tem quatro aspectos principais:

1. o homem está alienado da natureza;

2. está alienado de si mesmo (de sua própria atividade);

3. de seu "ser genérico" (de seu ser como membro da espécie humana);

4. o homem está alienado do homem (dos outros homens).

Para nós, educadores que temos sob nossos cuidados seres recémingressos no convívio social, é fundamental que possamos contribuir, desde a primeira escola, para a não alienação de si mesmos, da natureza, de seus companheiros de existência. É fundamental que nossa prática pedagógica possa alimentar a sua integridade humana. E esta integridade de corpoespírito-razão-emoção que favorece a cada sujeito c ao seu grupo social a capacidade desentir,pensar, e agir, de forma autônoma, crítica, criativa, inteligente, cooperativa. Favorece, portanto, o pleno exercício da cidadania.

Construir coletiva c permanentemente esta pedagogia é o nosso desafio de educadores comprometidos com a democracia. Um grande 
desafio, porque se move $\mathrm{cm}$ sentido inverso à engrenagem social de que somos parte.

Vivemos tempos difíceis, $\mathrm{cm}$ que a organização da sociedade urbana cada vez mais nos distancia de ura convívio necessário com a natureza e de um relacionamento expressivo com os outros seres, humanos c nãohumanos.

Nossa escola, da forma como está hoje estruturada, tem contribuído muito mais para reproduzir este estado de dispersão e fragmentação do que buscado intervir e transformar esse caminho.

Ate mesmo algumas propostas alternativas apresentadas como inovadoras, quando tratam da relação da criança com o espaço, com o meio ambiente, o fazem de forma pedagógica padronizada c limitada.

Quanto ao aspecto da relação criança/criança, também não oferecem oportunidades de vivência, exploração, movimentação, capazes de instituir uma nova maneira de se relacionar, de agir com os outros e com a natureza.

Novas pedagogias são importantes, e é fundamental que elas enfrentem e possam contribuir para reverter o processo de degradação severa da condição humana no planeta. Mais que reformas pedagógicas, precisamos de um verdadeiro descondicionamento de nossa situação pedagógica atual. Precisamos de novas referências que expandam a ação, o movimento e que libertem o pensamento e o desejo aprisionados, sufocados por uma sociedade embrutecida, regulada pela competição, pelo individualismo.

Precisamos de uma educação que pense a qualidade de vida, a qualidade do existir.

Referências bibliográficas

ARRUDA, Marcos. Metodologia da praxis e formação dos trabalhadores. Rio de Janeiro: PACS, 1988. mimeo.

Metodologia da praxis c educação popular libertadora na Nicarágua sandinista. Revista Vozes, Petrópolis, n.10, 1986.

CAPRA, Fritzof. O Tao da Física. São Paulo: Cultrix, 1983. 
GUATTARI, Félix. As três ecologias. Campinas: Papirus, 1990.

HERRIGEL, Eugen. A arte cavalheiresca do arqueiro Zen. Rio de Janeiro: Pensamento, 1975.

MÉSZÁROS, István. Marx: a teoria da alienação. Rio de Janeiro: Zahar, 1981.

TIR1BA, Léa. Buscando caminhos para a pré-escola popular. São Paulo: Ática, 1992.

TVIAVII. O Papalagui. Rio de Janeiro: Marco Zero, 1986.

Recebido em 21 de março de 1994

Mary Suely Barradas é psicóloga e mestre $\mathrm{cm}$ Psicologia da Educação pelo IESAE/FGV/RJ. Trabalha na rede pública da educação do município de Duque de Caxias-RJ e c colaboradora do Instituto de Políticas Alternativas para o Cone Sul (PACS).

Léa Tiriba é jornalista, educadora e mestre em Filosofia da Educação pelo IESAE/FGV/RJ. Coordena o Núcleo de Educação c Movimentos Sociais do Instituto de Políticas Alternativas Para o Cone Sul (PACS).

Given, on the one hand, the urgent need that social movenients formula te proposals for public policy on child education and pressure governmenis to iniplement these policies and, on the other hand, the need to ensure quality in services to children frecpienting daycare centers and pre-schools, this article aims to:l. outline a conception of integral education, one of whose central concerns is to construct a kind of coexistence with Nature in which people feel more part of, rather than lord over, Nature; 2. to offer some reflections on what we consider today to be the urgent need for educational practices that offer comfort and protection, as well as broader opportunities for movement, expression 
and integration with Nature; educational practices which preserve singularity, admire maus multiplicity, ensure the learning of cooperation and, thus, contribute to thefull exercise of citizenship.

Cet article tient compte, d'un côté, de l'urgence de laformulation par les mouvements sociaux de propositions de politiques publiques concernant l'éducation des enfants et de lapression que ces mouvements doivent exercer sur les gouvernements en vue de là mise en oeuvre de ces politiques et, $d$ 'un autre côté, du besoin d'assurer là qualité des prestations aux enfants qui sont déjà inscrits aux creches et à d'autres institutions d'enseignement pré-scolaire. Ainsi, cet article vise à: 1. prèsenter une conception d'éducation intégrale dont l'un des aspects essentiels est là construction d'une relation à là Nature quifasse de sorte que l'être humain se sente une part ie de celle-ci, et non pas son maítre; 2. prèsenter quelques réflexions basées sur ce que nous semble être un besoin actuellement pressant: là mise en place de pratiques éducatives capables d'offrir aux enfants aceneil et protection et d'augmenter leurs possibilites de mouvement, expression el integration à là nature; des pratiques éducatives quipréscrvent Ia singularité, admirent là multiplicitè humaine et assurent Vapprentissage de là cooperation, contribuant ainsi à l'exercice plein de là citoyenneté.

Considerando, por una parte, là necesidad urgente de que los movimientos Sociales formulai propuestas de políticas públicas para là educación de los ninos ypresionen a los gobiernos a implementarlas, y, por outra parte, considerando Ia necesidad de asegurar là calidad de los servidos que se prestan a los ninos que ya están en guarderías y parvularios, este artículo tiene el doble objetivo de: 1. presentar una Concepcion de educación integral, en que una de Ias Cuestiones centrales es Ia construcción de un convívio con là Naturaleza capaz de hacer que 
el ser humano se sienta parte de ella, y no su senor; 2. presentar algunas rejlexiones en base a Io que hoy consideramos como una necesidad apremiante: el surgimiento de prácticas educativas que, además de brindarles a los ninas acojida yprotección, amplien sus posibilidades de movimiento, expresión e integración a là naturaleza; prácticas educativas que preserven Ia singularidad, admiren là multiplicidad humana y aseguren el aprendizaje de là Cooperación, contribuyendo al pleno ejercicio de là ciudadanía. 